\title{
Visible-Light-Driven Transformations of Phenols via Energy Transfer Catalysis
}

\author{
Jérôme Fischer \\ Pierrick Nun \\ Vincent Coeffard* (1) \\ Université de Nantes, CEISAM UMR CNRS 6230, 44000 Nantes, \\ France \\ vincent.coeffard@univ-nantes.fr
}

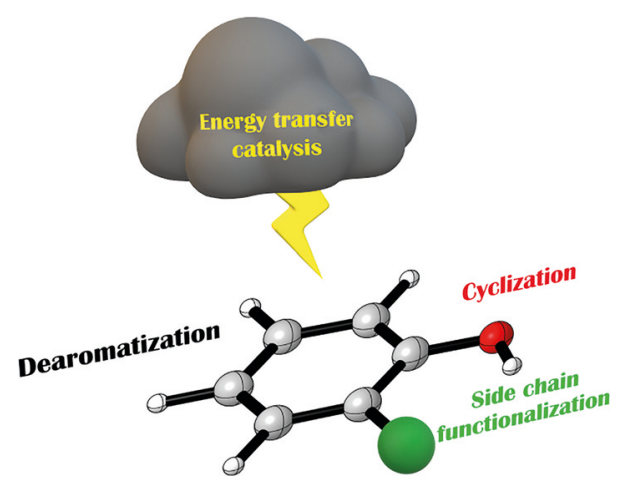

atively received less attention. Energy transfer catalysis involves the combination of a photosensitizer (PS), a substrate (S), and light. ${ }^{4}$ This photochemical process is based on the deactivation of an excited-light absorbing sensitizer (PS*) by transferring its energy to a substrate $\mathrm{S}$ leading to the formation of the excited substrate $S^{*}$ (Figure 1). Unlike photoredox catalysis, no single-electron transfer occurs between the excited photocatalyst and the substrate or any intermediates from the reaction mixture.

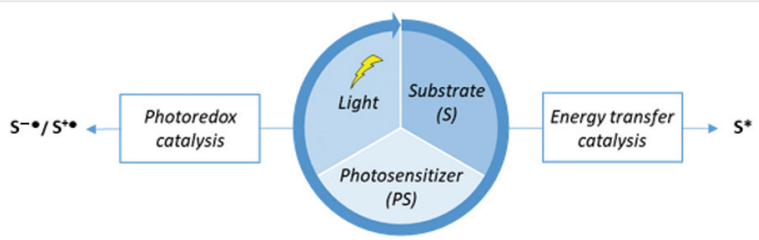

Figure 1 Energy transfer and photoredox catalysis

Breakthroughs in energy transfer catalysis have been driven by the design of new photosensitizers and the implementation of innovative synthetic transformations with applications in a range of contexts. ${ }^{5}$ By careful examination of the reaction conditions, visible-light-induced energy transfer catalysis has been harnessed in a series of transformations such as [2+2] photocycloadditions, alkene photoisomerizations, sensitization of metal complexes, oxidative processes through the formation of singlet oxygen, or the activation of azide and diazo compounds to form heterocyclic compounds. ${ }^{4}$ Amongst the substrates tested, phenol derivatives were deemed worthy of investigation because of their unique chemical behavior. Besides classical reactivities such as electrophilic aromatic substitutions ${ }^{6}$ and $\mathrm{C}-\mathrm{O}$ bond forming reactions, ${ }^{7}$ considerable attention has been given in recent years to dearomatization process$\mathrm{es}^{8}$ and direct $\mathrm{C}-\mathrm{H}$ functionalizations of the aromatic ring. ${ }^{9}$ 


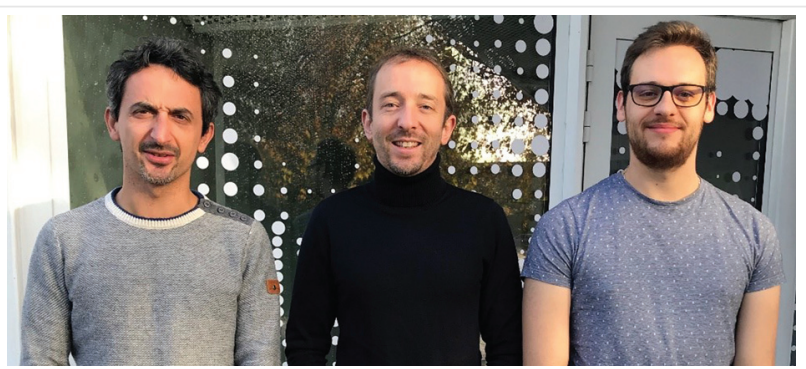

Vincent Coeffard (left) was born in Nantes (France) in 1981. He studied chemistry at Université de Nantes and completed his Ph.D. studies in 2007 in the group of Prof. Jean-Paul Quintard. He then moved to University College Dublin (Ireland) to work as a postdoctoral research fellow for two years in asymmetric catalysis under the guidance of Prof. Pat Guiry. He then spent ten months in Spain for a second postdoctoral experience in the group of Prof. Antonio M. Echavarren to investigate gold chemistry. In 2010, he was appointed CNRS researcher in the group of Prof. Christine Greck at Université de Versailles Saint-Quentinen-Yvelines (France) to work on the design of organocatalysts and implementation of catalytic technologies to access enantioenriched organic architectures. In 2016, he moved to Université de Nantes where his current research interests include asymmetric organocatalysis and photochemistry.

Pierrick Nun (middle) was born in Brest (France) in 1982. After undergraduate studies at Université de Nantes (France), he completed his Ph.D. in 2009 under the supervision of Dr. Frédéric Lamaty at Université de Montpellier (France), working on mechanical activation and solventfree synthesis. He then joined the group of Prof. Steven P. Nolan at the University of St. Andrews (Scotland) as a post-doctoral researcher. Following a second post-doctoral fellowship with Prof. Annie-Claude Gaumont at the Ecole Nationale Superieure d'Ingenieurs of Caen (France), he was appointed Assistant Professor at Université de Nantes and he is currently working on singlet oxygen applications in organic synthesis and medicine.

Jérôme Fischer (right) was born in 1994 in Mulhouse (France). After finishing his high school diploma, he studied chemistry at the Ecole Nationale Supérieure de Chimie of Mulhouse and joined the group of Dr. Vincent Coeffard for his Ph.D. studies in 2017. His research focuses on the design of new photosensitizers for applications in selective photooxidative processes.

In addition, recent advances regarding valorization of biomass to produce phenols have made these compounds attractive platforms in organic chemistry. ${ }^{10}$ The manifold reactivity of phenols with the synthetic appeal of energy transfer catalysis offers a powerful strategy to reach novel molecular architectures (Figure 2). This is the subject of this review, which does not intend to be comprehensive, but rather to point out the synthetic potential and future challenges of this methodology.

\section{Intermolecular Processes}

In intermolecular transformations, the reaction can be initiated by energy transfer from the excited triplet photosensitizer to the phenol-containing substrate or the reactant such as ground state triplet oxygen $\left({ }^{3} \mathrm{O}_{2}\right)$ leading to the

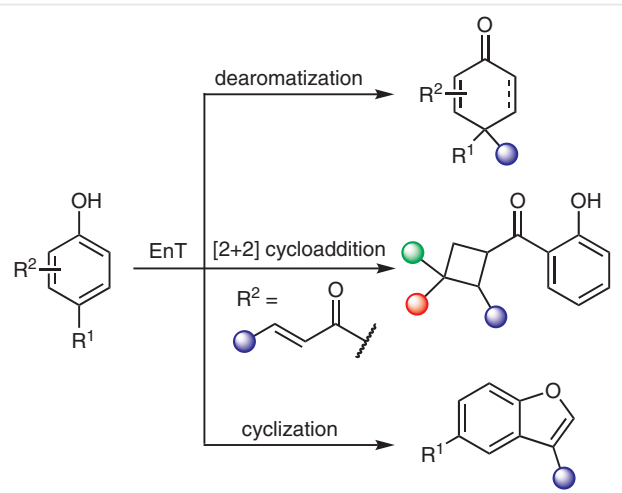

Figure 2 Phenol transformations via energy transfer catalysis

formation of the highly electrophilic species singlet oxygen $\left({ }^{1} \mathrm{O}_{2}\right)$. The two strategies will be discussed in the following examples.

\subsection{Reactions with Singlet Oxygen}

For many decades now, it has been demonstrated that singlet oxygen $\left({ }^{1} \mathrm{O}_{2}\right)$ is a powerful reactant toward electronrich substrates. ${ }^{11}$ An energy of $94 \mathrm{~kJ} \cdot \mathrm{mol}^{-1}$ is required to form the highly electrophilic singlet oxygen from ground state oxygen. Many photosensitizers (tetraphenylporphyrin, rose bengal, methylene blue to cite only a few) possess a triplet energy $\left(\mathrm{E}_{\mathrm{T}}\right)$ equal or greater than $94 \mathrm{~kJ} \cdot \mathrm{mol}^{-1}$ required to efficiently sensitize triplet oxygen into its singlet state. In synthetic chemistry, electron-rich phenols are prone to react with singlet oxygen and this research field has received considerable attention from a mechanistic and synthetic point of view.

In 2019, Dlugogorski and co-workers reported a mechanistic and kinetic study on the photooxygenation of phenol (Scheme 1, R = H). ${ }^{12}$ Based on DFT calculations and electron paramagnetic resonance (EPR), their results provided evidence for the 1,4-endoperoxide intermediate, obtained after a [4+2] cycloaddition, yielding $p$-benzoquinone as the only detected product after ring opening. Indeed, the 1,4-

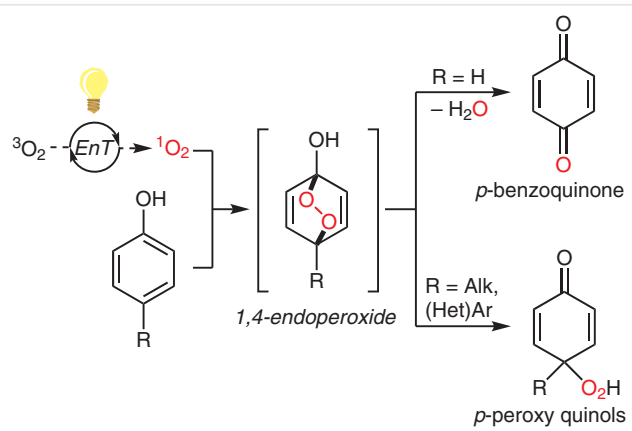

Scheme 1 Singlet-oxygen-mediated oxidation of phenols 
cycloaddition of ${ }^{1} \mathrm{O}_{2}$ at the ipso- and para-positions requires a $17-22 \mathrm{~kJ} \cdot \mathrm{mol}^{-1}$ lower energy barrier than the corresponding addition at the ortho and meta carbons.

When singlet oxygen reacts with para-substituted phenols, the in situ opening of the corresponding 1,4-endoperoxides results in the formation of $p$-peroxy quinols, that could then be reduced smoothly with triphenylphosphine or dimethyl sulfide to give the corresponding alcohols. ${ }^{13}$ The photooxidative dearomatization of para-substituted phenols with ${ }^{1} \mathrm{O}_{2}$ led to highly oxygenated frameworks and was subsequently applied as a key reaction in numerous multistep reactions as these structures can be found in many natural products. In this short review, we will focus our attention to the recent advances in ${ }^{1} \mathrm{O}_{2}$-mediated dearomatizations of para-substituted phenols.

As a first example, Kilic and co-workers prepared the hydroperoxides 2 after photooxygenation of the acetanilides 1 towards their syntheses of epoxy quinol antibiotics (Scheme 2).$^{14}$ This reaction was realized with tetraphenylporphyrin (TPP) ${ }^{15}$ as photosensitizer and no control on stereoselectivity was observed for this oxidation starting from a chiral substrate $\mathbf{1 b}$.

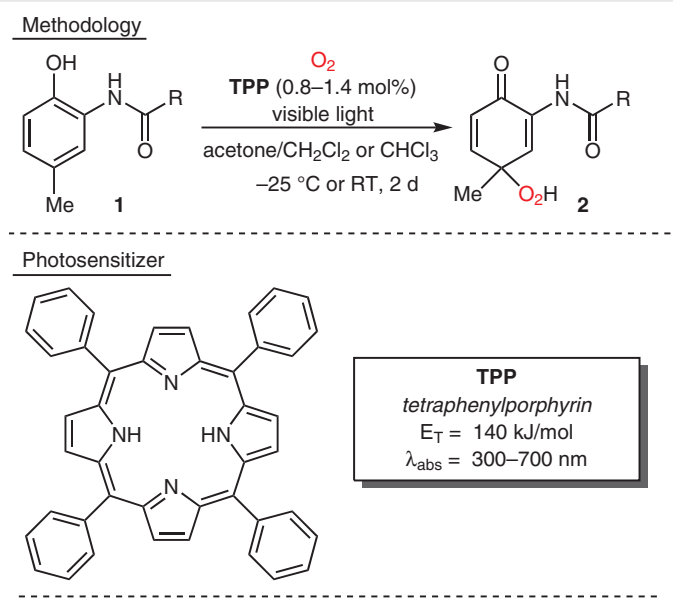

Examples<smiles>CC(=O)NC1=CC(C)(O)C=CC1=O</smiles>

2a, $62 \%$<smiles>CC(=O)OC(C)C(=O)NC1=CC(C)(O)C=CC1=O</smiles>

2b, $70 \%$
Scheme 2 Photooxygenation of acetanilides

The hydroperoxides $\mathbf{2}$ were then reduced to the corresponding alcohols, which underwent a Weitz-Scheffer epoxidation with tert-butyl hydroperoxide (TBHP) leading to the cis-epoxy quinols 3, important building blocks in Manumycin natural products (Scheme 3 ).

Oxidative dearomatization was also used by Hoye and co-workers in their synthesis of the polar pharmacophoric subunit of (+)-scyphostatin. ${ }^{16}$ The singlet-oxygen-mediated

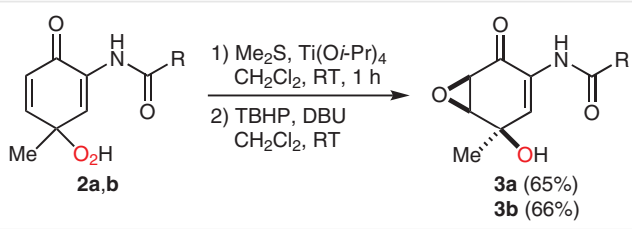

Scheme 3 Synthesis of cis-epoxy quinols

oxidation of 4 with rose bengal ${ }^{17}$ as photosensitizer under basic conditions followed by reduction with $\mathrm{Me}_{2} \mathrm{~S}$ was found as an efficient and atom economic alternative to a classical phenyliodine diacetate oxidation (Scheme 4).

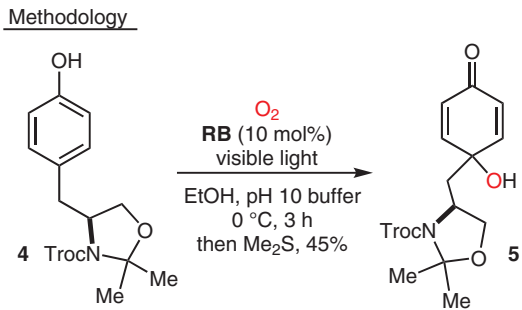

Photosensitizer

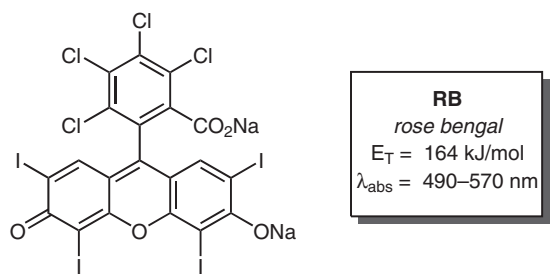

Scheme 4 Oxidative dearomatization of 4

Following these results, Klussmann and co-workers described in 2013 a sequence of peroxide formation, reduction, and intramolecular cyclization of $\mathbf{6}$ to give access to oxaspirocycles 7 (Scheme 5). ${ }^{18}$ This sequence could be exe-

Methodology

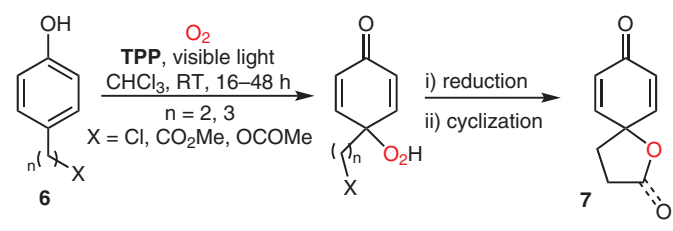

Application

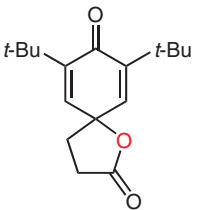

$7 a(74 \%$, one pot)

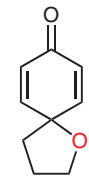

7b $(50 \%$, one pot)

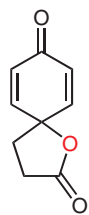

7c $(72 \%)$
Scheme 5 Oxaspirocycles synthesis via a photooxygenation/reduction/cyclization sequence 
cuted stepwise or more conveniently in a one-pot fashion, without isolation of the hydroperoxide intermediates. Here again, the key oxidative dearomatization is an atom-economic alternative to hypervalent iodine reactants. Although the scope is limited to 3 examples of oxaspirocyclic compounds 7, it demonstrated the potential of photosensitized dearomatization of phenols to obtain more complex structures.

Singlet-oxygen chemistry has been harnessed in total synthesis of natural and biologically relevant products. ${ }^{19}$ For instance, an elegant diastereoselective visible-light-induced oxidative dearomatization was observed by the group of Li during their synthesis of the tricyclic framework contained in tiglianes and daphnanes (Scheme 6). ${ }^{20}$ Using TPP as photosensitizer in chloroform under a strong visible light, irradiation followed by reduction of the corresponding $p$-peroxy quinol led to the alcohol $\mathbf{9}$ as a single diastereoisomer in a high yield (74\%). The relative configuration was established by X-ray diffraction analysis, and it was assumed that this stereoselectivity was due to the trimethylsilyl ether moiety and its steric hindrance on one face of the phenol, leading singlet oxygen to react on the other face.

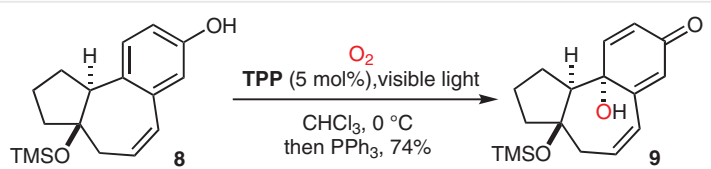

Scheme 6 Oxidative dearomatization towards the synthesis of tigliane and daphnane diterpenes

Another diastereoselective oxidative transformation was conducted as a key step in the synthesis of erythrina alkaloids by the group of Kitamura and Fukuyama (Scheme 7). ${ }^{21}$ Here again, the steric hindrance around the phenol has a strong influence on the stereoselective ${ }^{1} \mathrm{O}_{2}$ addition. An Xray analysis confirmed that the silyloxy group is pointing toward the phenol moiety. This configuration and the atropoisomeric stereochemistry guided singlet oxygen to react specifically on one face of $\mathbf{1 0}$ to give selectively a peroxide that led to a spontaneous reaction with the amide nitrogen yielding efficiently 11 (77\%) as a single diastereomer.

Inspired by these results, we reported in 2018 a one-pot Bodipy-catalyzed domino photooxygenation. ${ }^{22} \mathrm{~A}$ photosensitized singlet-oxygen-mediated phenol dearomatization, followed by a [4+2] cycloaddition gave a variety of sixmembered-ring-fused furans 13 under mild conditions (Scheme 8 ). The best results were obtained by using the readily available Bodipy PS1 as a photosensitizer. ${ }^{23}$ Starting from 2-alkenylphenols 12, we envisioned that a first singlet oxygen molecule would react as previously described with the more electron-rich phenol, giving the corresponding hydroperoxide $\mathbf{A}$. A second singlet oxygen molecule could then react with these intermediates in a classical [4+2]

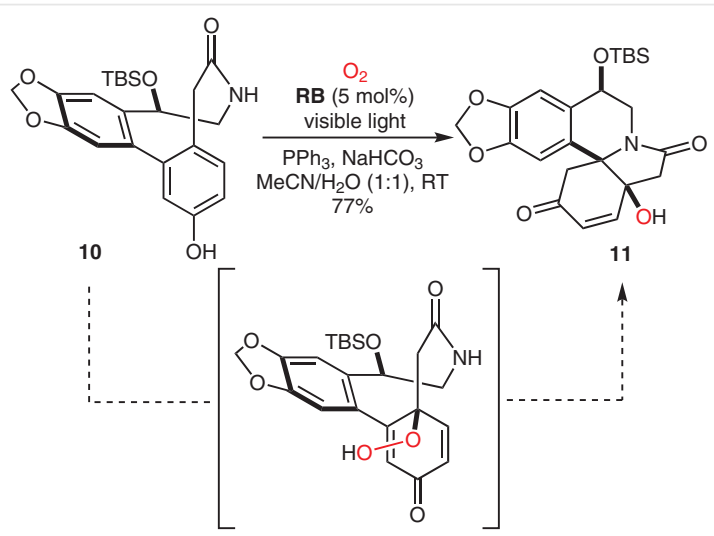

Scheme 7 Multibond-forming process

cycloaddition that would ultimately render the fused furans 13 after reduction. Mechanistic studies were carried out to outline the importance of singlet oxygen in the reaction outcome.

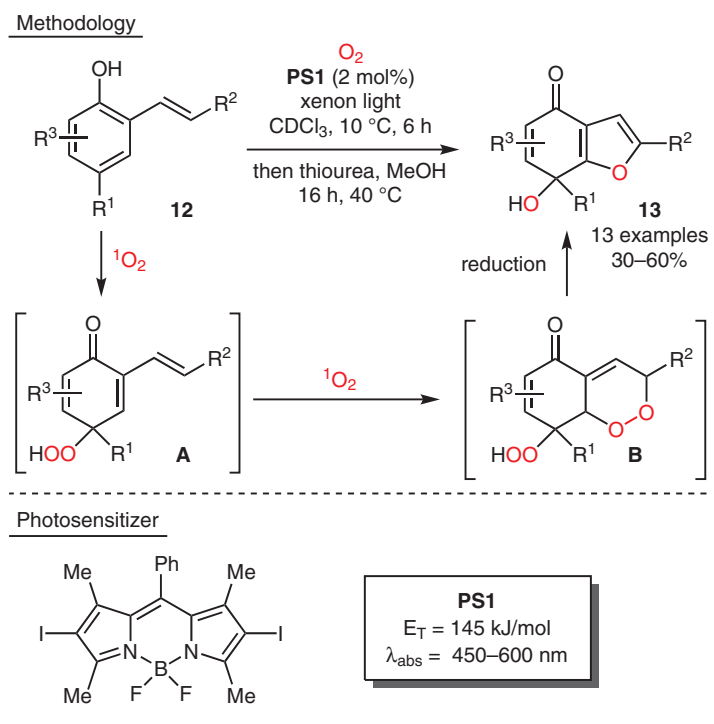

Selected examples

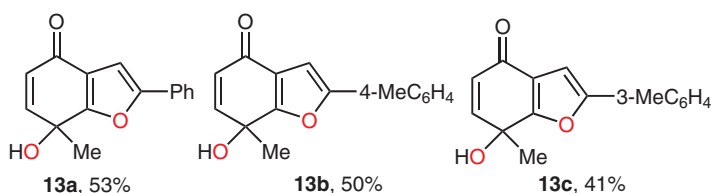

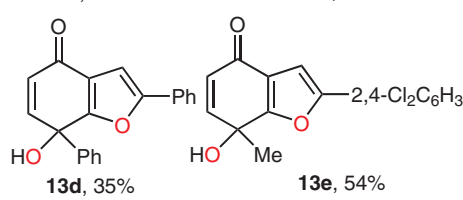<smiles>CC1=CC(=O)c2cc(-c3ccccc3)oc2C1(O)[N+](=O)[O-]</smiles>

Scheme 8 Catalyzed domino photooxygenation 
Methodology

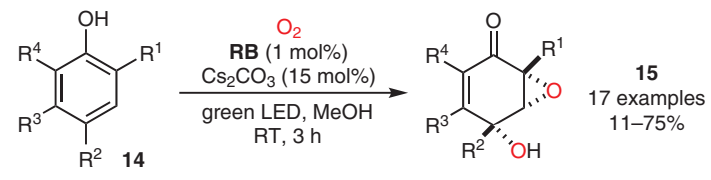

Selected examples

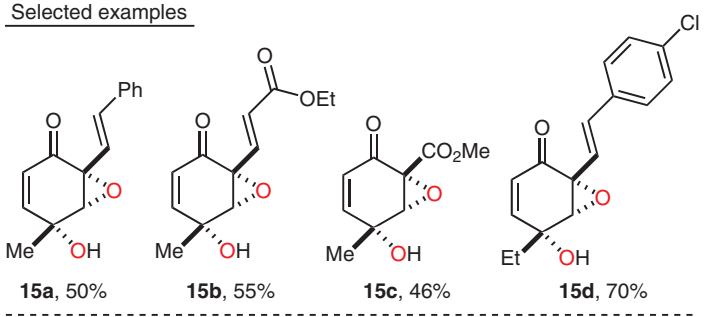

Proposed mechanism

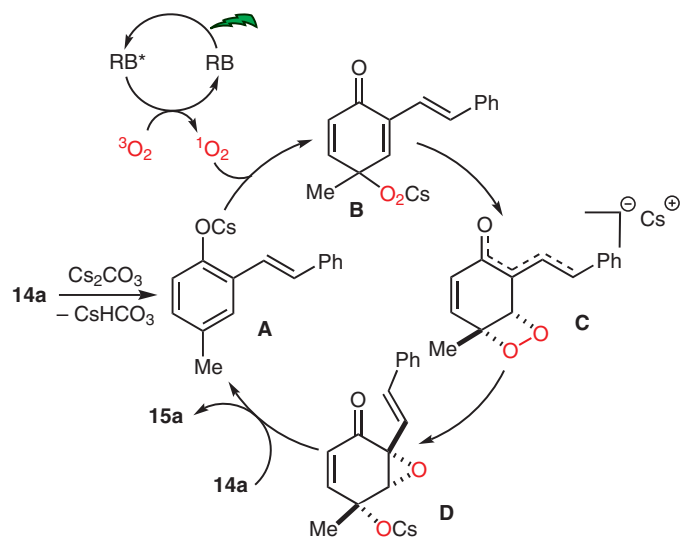

Scheme 9 Epoxyquinol synthesis via photooxygenation under basic conditions
The importance of functionalized epoxyquinol frameworks in natural products served to challenge synthetic organic chemists. ${ }^{24}$ Previous reports have shown that phenols were interesting substrates to get access to epoxyquinols through a ${ }^{1} \mathrm{O}_{2}$-mediated dearomatization/reduction/epoxidation sequence (Schemes 2 and 3). Nevertheless, the reduction/oxidation tactic lowers the synthetic appeal of this strategy. In order to harness the full potential of singlet oxygen by transferring both oxygen atoms, we reported a onepot synthesis of cis-epoxyquinols $\mathbf{1 5}$ starting from phenols 14 (Scheme 9). ${ }^{25}$ The key point for the success of the reaction lies in the use of basic conditions.

After optimization studies and mechanistic insights, we demonstrated that using rose bengal as photosensitizer and cesium carbonate as base led to a large scope of functionalized epoxyquinols. Cesium carbonate plays a pivotal role by increasing the kinetic of the photooxygenation step while triggering the epoxidation reaction.

\section{$2.2[2+2]$ Cycloadditions}

A second class of reactions initiated by energy transfer is [2+2] cycloaddition reactions. Contrary to photoredox strategies, visible-light photocatalyzed [2+2] cycloadditions by energy transfer are not limited by electrochemical potentials. This was demonstrated by the breakthrough work of Yoon and co-workers who developed a two-catalyst strategy for enantioselective cycloadditions of phenol derivatives 16. ${ }^{26}$ Indeed, scandium(III) salts in the presence of a chiral ligand formed a chiral Lewis acid acting as a catalyst for inducing enantioselectivities (Scheme 10). ${ }^{27} \mathrm{~A}$ large di-
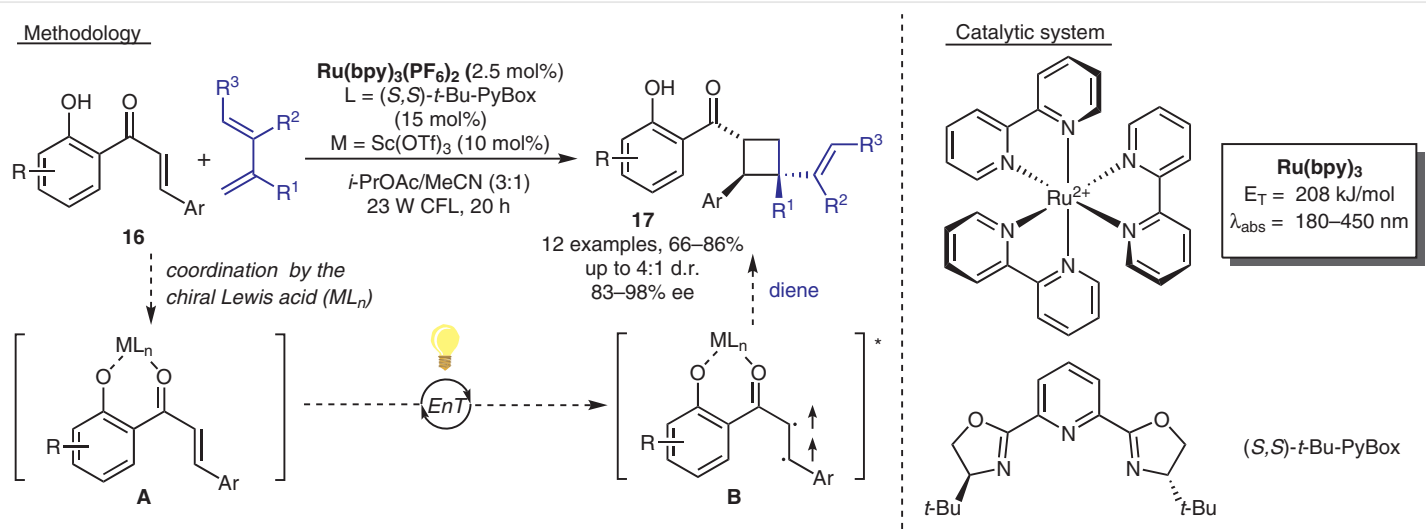

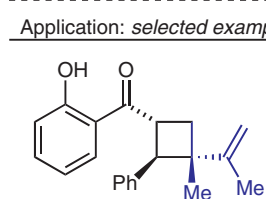

$17 a, 84 \%$

$93 \%$ ee, $3: 1$ d.r.

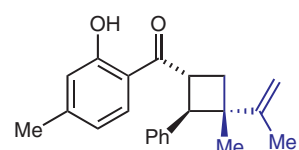

$17 b, 86 \%$

$83 \%$ ee, $2: 1$ d.r.

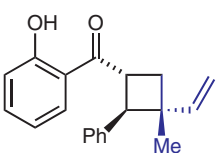

$17 c, 92 \%$

84\% ee, $3: 1$ d.

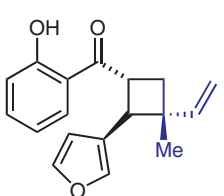

17d, $82 \%$

$85 \%$ ee, $4: 1$ d.r.

Scheme 10 Enantioselective [2+2] cycloadditions through Lewis acid catalyzed triplet energy transfer

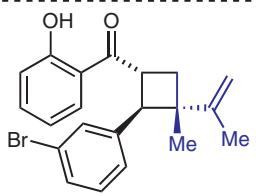

17 e, $72 \%$

93\% ee, 3:1 d.r. 
versity of asymmetric [2+2] cycloadditions was conducted on diversely substituted phenol derivatives $\mathbf{1 6}$ and dienes.

After mechanistic and computational investigations, they demonstrated that complexation of $\mathbf{1 6 a}$ with $\mathrm{Sc}$ (III) salts results in a dramatic decrease in the energy of the triplet state, from $\mathrm{E}_{\mathrm{T}}(\exp )=54 \mathrm{kcal} / \mathrm{mol}$ to $32 \mathrm{kcal} / \mathrm{mol}$. No reaction occurred in the absence of any Lewis acid as well as in the absence of light. The formation of the chiral complex A involving the $\mathrm{Sc}$ (III) salt, the chiral PyBox ligand, and the two oxygens of the 2'-hydroxychalcone $\mathbf{1 6}$ is probably the key intermediate, leading the [2+2] cycloaddition to proceed in an enantioselective way.

Very recently, Chen, Shen, and co-workers carried out a detailed computational study on the mechanism of this transformation. ${ }^{28}$ Among many other data, they explained the origin of chirality in this reaction by energy changes in the triplet state depending of the attacked side of the coordinated chalcone.

In a further study, the group of Yoon extended the scope of the reaction to various styrenes and diene systems, obtaining high enantiomeric excesses and giving a direct access to diarylcyclobutane natural products (Scheme 11). ${ }^{29}$ Following Yoon's pioneering works, Feng, Liu and co-workers also reported an enantioselective [2+2] cycloaddition involving 2'-hydroxychalcones $\mathbf{1 6}$ (Scheme 12). ${ }^{30}$

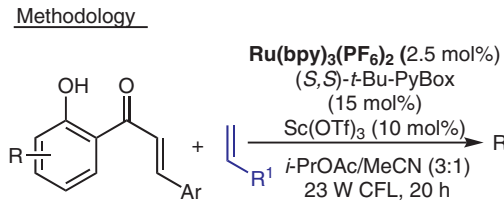

16 up to $>10: 1$ d.r. up to $>99 \%$ ee

Application: selected examples

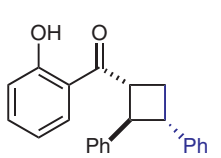

18a, $88 \%$

$>99 \%$ ee, $2: 1$ d.r.

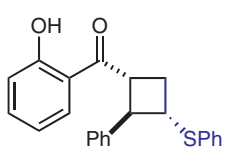

$18 c, 86 \%$

$93 \%$ ee, $1: 1$ d.r.

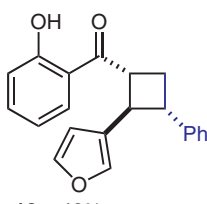

$18 \mathrm{e}, 42 \%$

94\% ee, $2: 1$ d.r.

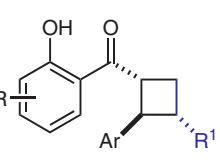

18 


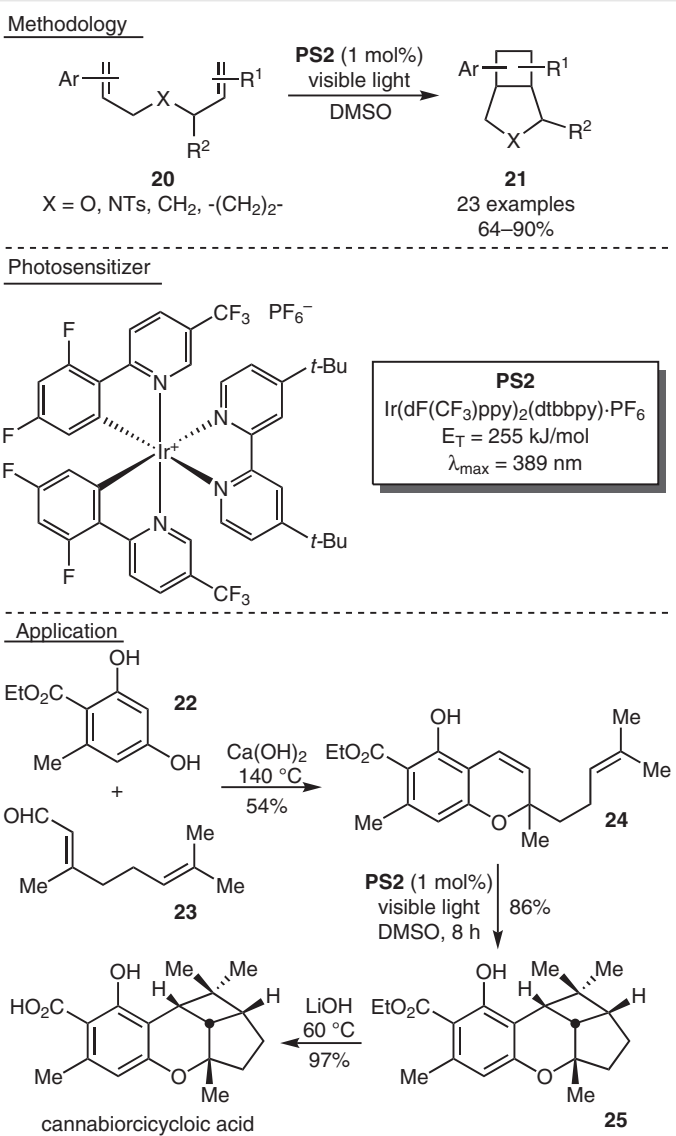

Scheme 13 Synthesis of cannabiorcicycloic acid using a [2+2] photocycloaddition as the key step

strategy has been harnessed by Mouriès-Mansuy, Ollivier, Fensterbank, and co-workers for the $\mathrm{Au}(\mathrm{I})$-catalyzed formation of alkynylbenzofuran derivatives 27 (Scheme 14). ${ }^{33}$ The combination of electrophilic gold catalysis and photosensitization by means of PS2 allowed the formation of the decorated benzofurans 27 starting from phenols 26 and alkynyl iodide partners. The optimized reaction conditions were applied to a series of substrates and moderate-to-excellent yields of the desired alkynylbenzofurans were obtained. While a wide substrate scope was observed, no reaction occurred with an iodoalkyne bearing a 4-nitroaryl group and the protodeauration cyclization product was formed.

Detailed mechanistic investigations were carried out to shed light on the formation of $\mathbf{2 7}$ by performing control experiments, photophysical analyses and modelling studies. The reaction sequence would start by the 5-endo-dig goldcatalyzed O-cyclization of $\mathbf{2 6}$ to afford the vinylgold(I) species A. A Dexter-type energy transfer between this intermediate and the long-lived triplet state ${ }^{3}[\mathrm{Ir}-\mathrm{F}]$ would occur to afford the excited state of the vinylgold(I) species B, a key

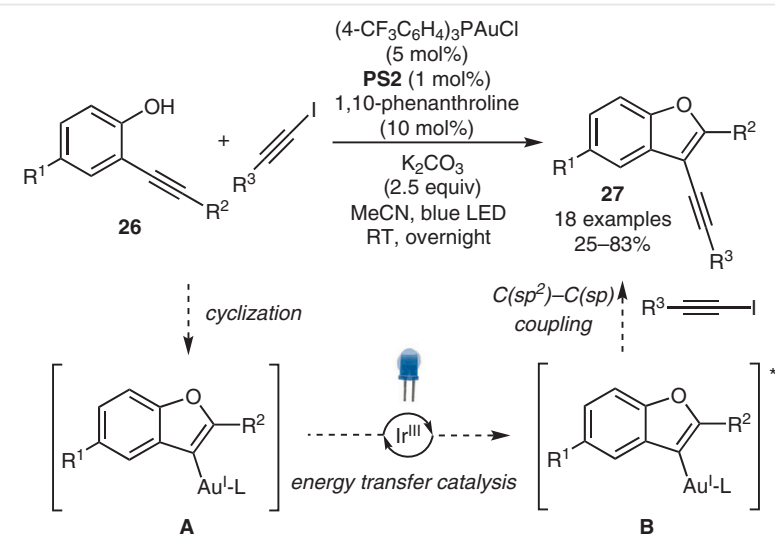

Scheme 14 Merging electrophilic gold catalysis and photosensitization to prepare alkynylbenzofurans

intermediate for triggering the oxidative addition. Gold(I) complexes are rather reluctant to oxidative addition and therefore, specific reactions conditions are generally required to provide the corresponding gold(III) intermediates. Given that triplet sensitization can promote oxidative addition under convenient conditions, this strategy should offer new synthetic opportunities in the near future.

\section{Conclusions and Outlook}

This review has brought to light recent advances in visible-light-mediated transformation of phenols by energy transfer catalysis. The unique properties of phenols enabled their transformation into synthetically interesting directions. The hydroxyl group directly attached to the aromatic ring makes phenols electron rich compounds and this property was harnessed in dearomatization reactions by means of singlet oxygen. The hydroxyl group was also involved in 0 -cyclization reactions and in chelate complexes as key intermediates to deliver [2+2] photocyclized adducts with excellent selectivities. As energy transfer is not limited by the redox properties of the substrates, energy transfer catalysis has a bright future in organic synthesis and therefore in phenol chemistry. For instance, the design of new catalytic systems is expected to tackle the challenge of asymmetric photooxygenation of aromatic compounds such as phenols This review aimed at collecting examples of visible-lightdriven transformations of phenols via energy transfer catalysis and in the near future, we hope that new examples will show off the synthetic potential of this strategy.

\section{Funding Information}

This work was supported by The Région Pays de la Loire (NANO2 project) which financed a Ph.D. grant for J.F. We also thank University of Nantes and CNRS for financial support. 


\section{Acknowledgment}

Dr. Loïc Pantaine is gratefully acknowledged for proofreading the manuscript.

\section{References}

(1) For selected references, see: (a) Visible Light Photocatalysis in Organic Chemistry; Stephenson, C. R. J.; Yoon, T. P.; MacMillan, D. W. C., Ed.; Wiley-VCH: Weinheim, 2018. (b) Glusac, K. Nat. Chem. 2016, 8, 734. (c) Skubi, K. L.; Blum, T. R.; Yoon, T. P. Chem. Rev. 2016, 116, 10035. (d) Kärkäs, M. D.; Porco, J. A.; Stephenson, C. R. J. Chem. Rev. 2016, 116, 9683. (e) Douglas, J. J.; Sevrin, M. J.; Stephenson, C. R. J. Org. Process Res. Dev. 2016, 20, 1134. (f) Bach, T. Angew. Chem. Int. Ed. 2015, 54, 11294. (g) Bach, T.; Hehn, J. P. Angew. Chem. Int. Ed. 2011, 50, 1000. (h) Hoffmann, N. Chem. Rev. 2008, 108, 1052.

(2) (a) Marzo, L.; Pagire, S. K.; Reiser, O.; König, B. Angew. Chem. Int. Ed. 2018, 57, 10034. (b) Schultz, D. M.; Yoon, T. P. Science 2014, 343, 1239176. (c) Yoon, T. P.; Ischay, M. A.; Du, J. Nat. Chem. 2010, 2, 527. (d) Ravelli, D.; Dondi, D.; Fagnoni, M.; Albini, A. Chem. Soc. Rev. 2009, 38, 1999.

(3) (a) Nicholls, T. P.; Leonori, D.; Bissember, A. C. Nat. Prod. Rep. 2016, 33, 1248. (b) Shaw, M. H.; Twilton, J.; MacMillan, D. W. C. J. Org. Chem. 2016, 81, 6898. (c) Tucker, J. W.; Stephenson, C. R. J. J. Org. Chem. 2012, 77, 1617. (d) Xuan, J.; Xiao, W.-J. Angew. Chem. Int. Ed. 2012, 51, 6828. (e) Narayanam, J. M. R.; Stephenson, C. R. J. Chem. Soc. Rev. 2011, 40, 102.

(4) (a) Zhou, Q.-Q.; Zou, Y.-Q.; Lu, L.-Q.; Xiao, W.-J. Angew. Chem. Int. Ed. 2019, 58, 1586. (b) Strieth-Kalthoff, F.; James, M. J.; Teders, M.; Pitzer, L.; Glorius, F. Chem. Soc. Rev. 2018, 47, 7190.

(5) For selected recent examples, see: (a) Faßbender, S. I.; Molloy, J. J.; Mück-Lichtenfeld, C.; Gilmour, R. Angew. Chem. Int. Ed. 2019, 58, 18619. (b) Oderinde, M. S.; Kempson, J.; Smith, D.; Meanwell, N. A.; Mao, E.; Pawluczyk, J.; Vetrichelvan, M.; Pitchai, M.; Karmakar, A.; Rampulla, R.; Li, J.; Dhar, T. G. M.; Mathur, A. Eur. J. Org. Chem. 2020, 41. (c) Day, J. I.; Singh, K.; Trinh, W.; Weaver, J. D. J. Am. Chem. Soc. 2018, 140, 9934. (d) James, M. J.; Schwarz, J. L.; Strieth-Kalthoff, F.; Wibbeling, B.; Glorius, F. J. Am. Chem. Soc. 2018, 140, 8624. (e) Hörmann, F. M.; Chung, T. S.; Rodriguez, E.; Jakob, M.; Bach, T. Angew. Chem. Int. Ed. 2018, 57, 827. (f) Molloy, J. J.; Metternich, J. B.; Daniliuc, C. G.; Watson, A. J. B.; Gilmour, R. Angew. Chem. Int. Ed. 2018, 57, 3168. (g) Denisenko, A. V.; Druzhenko, T.; Skalenko, Y.; Samoilenko, M.; Grygorenko, O. O.; Zozulya, S.; Mykhailiuk, P. K. J. Org. Chem. 2017, 82, 9627. (h) Huang, X.; Quinn, T. R.; Harms, K.; Webster, R. D.; Zhang, L.; Wiest, O.; Meggers, E. J. Am. Chem. Soc. 2017, 139, 9120. (i) Skubi, K. L.; Kidd, J. B.; Jung, H.; Guzei, I. A.; Baik, M.-H.; Yoon, T. P. J. Am. Chem. Soc. 2017, 139, 17186. (j) Bagal, D. B.; Park, S.-W.; Song, H.-J.; Chang, S. Chem. Commun. 2017, 53, 8798. (k) Welin, E. R.; Le, C.; Arias-Rotondo, D. M.; McCusker, J. K.; MacMillan, D. W. C. Science 2017, 355, 380. (l) Luis-Barrera, J.; Laina-Martín, V.; Rigotti, T.; Peccati, F.; Solans-Monfort, X.; Sodupe, M.; Mas-Ballesté, R.; Liras, M.; Alemán, J. Angew. Chem. Int. Ed. 2017, 56, 7826.

(6) Weber, M.; Weber, M.; Kleine-Boymann, M. Phenol, In Ullmann's Encyclopedia of Industrial Chemistry, Vol. 26; Wiley-VCH: Weinheim, 2004, 503-519.

(7) Sambiagio, C.; Marsden, S. P.; Blacker, A. J.; McGowan, P. C. Chem. Soc. Rev. 2014, 43, 3525.
(8) (a) Sun, W.; Li, G.; Hong, L.; Wang, R. Org. Biomol. Chem. 2016, 14, 2164. (b) Wu, W.-T.; Zhang, L.; You, S.-L. Chem. Soc. Rev. 2016, 45, 1570. (c) Pouységu, L.; Deffieux, D.; Quideau, S. Tetrahedron 2010, 66, 2235.

(9) Huang, Z.; Lumb, J.-P. ACS Catal. 2019, 9, 521.

(10) Amen-Chen, C.; Pakdel, H.; Roy, C. Bioresour. Technol. 2001, 79, 277.

(11) Singlet Oxygen: Applications in Biosciences and Nanosciences; Nonell, S.; Flors, C., Ed.; The Royal Society of Chemistry: Cambridge, 2016.

(12) Al-Nu'airat, J.; Dlugogorski, B. Z.; Gao, X.; Zeinali, N.; Skut, J.; Westmoreland, P. R.; Oluwoye, I.; Altarawneh, M. Phys. Chem. Chem. Phys. 2019, 21, 171.

(13) (a) Barradas, S.; Carreño, M. C.; González-López, M.; Latorre, A.; Urbano, A. Org. Lett. 2007, 9, 5019. (b) Carreño, M. C.; GonzálezLópez, M.; Urbano, A. Angew. Chem. Int. Ed. 2006, 45, 2737.

(14) (a) Zilbeyaz, K.; Sahin, E.; Kilic, H. Tetrahedron: Asymmetry 2007, 18, 791. (b) Adam, W.; Kilic, H.; Saha-Möller, C. R. Synlett 2002, 510.

(15) Arbogast, J. W.; Darmanyan, A. P.; Foote, C. S.; Diederich, F. N.; Whetten, R. L.; Rubin, Y.; Alvarez, M. M.; Anz, S. J. J. Phys. Chem. 1991, 95, 11.

(16) Hoye, T. R.; Jeffrey, C. S.; Nelson, D. P. Org. Lett. 2010, 12, 52.

(17) Chen, Y.; Urano, T.; Karatsu, T.; Takahara, S.; Yamaoka, T.; Tokumaru, K. J. Chem. Soc., Perkin Trans. 2 1998, 2233.

(18) Jones, K. M.; Hillringhaus, T.; Klussmann, M. Tetrahedron Lett. 2013, 54, 3294.

(19) (a) For a review, see: Ghogare, A. A.; Greer, A. Chem. Rev. 2016, 116, 9994. For other examples of photooxygenation of parasubstituted phenol as a key step in total synthesis, see: (b) Park, K. H.; Chen, D. Y.-K. Chem. Commun. 2018, 54, 13018. (c) Cabrera-Afonso, M. J.; Lucena, S. R.; Juarranz, Á.; Urbano, A.; Carreño, M. C. Org. Lett. 2018, 20, 6094. (d) Kimishima, A.; Umihara, H.; Mizoguchi, A.; Yokoshima, S.; Fukuyama, T. Org. Lett. 2014, 16, 6244.

(20) Tong, G.; Liu, Z.; Li, P. Org. Lett. 2014, 16, 2288.

(21) Umihara, H.; Yoshino, T.; Shimokawa, J.; Kitamura, M.; Fukuyama, T. Angew. Chem. Int. Ed. 2016, 55, 6915.

(22) Mauger, A.; Farjon, J.; Nun, P.; Coeffard, V. Chem. Eur. J. 2018, 24, 4790.

(23) Wu, W.; Guo, H.; Wu, W.; Ji, S.; Zhao, J. J. Org. Chem. 2011, 76, 7056.

(24) Mehta, G.; Sengupta, S. Tetrahedron 2017, 73, 6223.

(25) Péault, L.; Nun, P.; Le Grognec, E.; Coeffard, V. Chem. Commun. 2019, 55, 7398.

(26) Blum, T. R.; Miller, Z. D.; Bates, D. M.; Guzei, I. A.; Yoon, T. P. Science 2016, 354, 1391.

(27) Kirgan, R. A.; Witek, P. A.; Moore, C.; Rillema, D. P. Dalton Trans. 2008, 3189.

(28) Ma, L.; Fang, W.-H.; Shen, L.; Chen, X. ACS Catal. 2019, 9, 3672.

(29) Miller, Z. D.; Lee, B. J.; Yoon, T. P. Angew. Chem. Int. Ed. 2017, 56, 11891.

(30) Yu, H.; Dong, S.; Yao, Q.; Chen, L.; Zhang, D.; Liu, X.; Feng, X. Chem. Eur. J. 2018, 24, 19361.

(31) Lu, Z.; Yoon, T. P. Angew. Chem. Int. Ed. 2012, 51, 10329.

(32) Kancherla, R.; Muralirajan, K.; Sagadevan, A.; Rueping, M. Trends Chem. 2019, 1, 510.

(33) Xia, Z.; Corcé, V.; Zhao, F.; Przybylski, C.; Espagne, A.; Jullien, L.; Le Saux, T.; Gimbert, Y.; Dossmann, H.; Mouriès-Mansuy, V.; Ollivier, C.; Fensterbank, L. Nat. Chem. 2019, 11, 797. 